médio de follow-up de 12 anos, seis casos foram considerados sucessos clínicos, que está de acordo com o descrito na literatura. O insucesso reportado permitiu a manutenção do dente em função por um período de 5 anos, possibilitando uma reabilitação final com melhor prognóstico. A conjunção de apexificação e restauração corono-radicular adesiva permitiu uma elevada taxa de sucesso e sobrevivência por um longo período de tempo permitindo uma melhor qualidade de vida destes doentes.

http://doi.org/10.24873/j.rpemd.2018.11.387

\section{\#SPE-07 Tratamento Conservador de uma Reabsorção Cervical Invasiva Classe 1 de Heithersay}

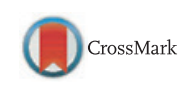

Salomé Ferreira ${ }^{1}$, Laura Semide ${ }^{1}$, Sofia Mendes Fernandes ${ }^{2}$, Luís Corte-Real ${ }^{3}$, Arnaldo Sousa ${ }^{4}$

${ }^{1}$ Licenciatura em Medicina Dentária / Aluna da Pós-Graduação em Endodontia IUCS-CESPU; ${ }^{2}$ Mestrado Integrado em Medicina Dentária / Aluna da Pós- Graduação em Endodontia IUCS-CESPU; ${ }^{3}$ Mestrado em Endodontia / Docente da Pós-Graduação em Endodontia IUCS-CESPU; ${ }^{4}$ Doutorado em Odontoestomatologia / Docente da Pós-Graduação em Endodontia IUCS-CESPU

Introdução: A reabsorção cervical invasiva é uma condição dinâmica e complexa, caracterizada pela invasão do precemento radicular por tecido fibrovascular do ligamento periodontal.

Descrição de caso clínico: Paciente do sexo feminino de 21 anos foi referenciada para a consulta de Endodontia por sintomatologia leve ao frio no dente 21 . Ao exame clínico foi detetada uma mancha rosa na zona cervical do dente e retração gengival. Foram realizadas radiografias periapicais e imagens tridimensionais com recurso a tomografia axial computorizada dental scan do maxilar superior. Foi diagnosticada uma reabsorção cervical invasiva classe 1 de Heithersay com origem no trauma oclusal devido a um aumento da sobremordida vertical. O tratamento consistiu na realização de um retalho de base papilar para exposição da lesão, a qual foi removida inicialmente com brocas diamantadas e depois com brocas laminadas de contra-ângulo. A cavidade foi preenchida com um forro de ionómero de vidro e com resina composta e o retalho foi suturado. No follow-up de 1 ano o dente encontra-se assintomático e em função.

Discussão e Conclusão: A etiologia da reabsorção inflamatória externa é desconhecida, mas foram identificados vários fatores predisponentes como branqueamento interno, trauma e tratamentos ortodônticos. Uma mancha rosa na coroa dentária é o indício clínico da presença deste tipo de lesão e radiograficamente apresenta-se como uma lacuna na região cervical do dente. A abordagem da lesão depende da sua classificação sendo que para a reparação de uma lesão de classe 1 de Heithersay, sem envolvimento pulpar, é necessário realizar a exposição cirúrgica da lacuna, remover o tecido de granulação e restaurar o defeito recorrendo à realização de uma cavidade que deverá ser preenchida com um material restaurador. Neste caso consideramos o prognóstico reservado já que após a recuperação da lesão a doente deu início a um tratamento ortodôntico.

http://doi.org/10.24873/j.rpemd.2018.11.388
\#SPE-08 Método alternativo para remoção de um instrumento fraturado: a propósito de um caso clínico

Meirinhos $\mathrm{J}^{1}$, Martins JC ${ }^{1}$, Pires $\mathrm{MD}^{1}$, Rito Pereira, $\mathrm{M}^{2}$, Ginjeira $\mathrm{A}^{3}$

${ }^{1}$ Aluno(a) de Pós Graduação de Especialização em Endodontia, Faculdade de Medicina Dentária, Universidade de Lisboa; ${ }^{2}$ Assistente convidado da Pós Graduação de Especialização em Endodontia, Faculdade de Medicina Dentária, Universidade de Lisboa; ${ }^{3}$ Regente da Pós Graduação de Especialização em Endodontia, Faculdade de Medicina Dentária, Universidade de Lisboa

Introdução: Num tratamento endodôntico, durante a fase de instrumentação do sistema canalar, a possibilidade de fratura de um instrumento está sempre presente. Quando ocorre, leva, primeiro, ao aumento de ansiedade por parte do clínico, como também à obstrução do canal, dificultando, assim, a completa desinfeção do mesmo. É, por isso, importante perceber as causas que provocam esta complicação (fratura por torsão / fratura por fadiga cíclica), bem como as diferentes possibilidades de tratamento que possuímos para a sua resolução. Desde o "bypass" do instrumento, à tentativa de remoção, a microcirurgia, a monitorização / controlo da peça dentária até a sua extração, são várias as opções que o Médico Dentista tem ao seu dispor para solucionar o caso. O objetivo deste caso clínico é apresentar uma alternativa simples na remoção de instrumentos fraturados no interior do canal radicular, utilizando uma agulha de irrigação e cola de cianoacrilato.

Descrição do caso clínico: Paciente do género feminino, 58 anos, dirigiu-se à consulta da Pós Graduação de Especialização em Endodontia da Faculdade de Medicina Dentária da Universidade de Lisboa (FMDUL), reencaminhada por uma colega. No exame radiográfico, o segundo pré molar superior direito apresentava um instrumento fraturado localizado no terço médio do canal vestibular. Como plano de tratamento foi sugerido tratamento endodôntico não cirúrgico. O tratamento foi efetuado sob isolamento total e ampliação com microscópio operatório, em quatro consultas. Foi tentado, sem sucesso, o "bypass" do instrumento, bem como a sua remoção utilizando diversos sistemas: IRS (Instrument Removal System, Dentsply Endodontics, Tulsa, OK, USA), pontas ultrassónicas ProUltra (Dentsply Tulsa Dental; Tulsa, Oklahoma) e limas K (Dentsply Maillefer, Ballaigues, Switzerland) acopladas ao Endo-chuck (SybronEndo; Orange, California). Com o recurso a uma agulha de irrigação 27-G (BD MicrolanceTM 3 Needles 27G X 3/4" $0,4 \mathrm{~mm}$ X $19 \mathrm{~mm}$ ) e cola de cianoacrilato (Cobra Pacific Super Glue) foi possível remover o fragmento. O dente foi devidamente instrumentado, desinfetado, obturado com gutta percha e posteriormente restaurado directa e e definitivamente com resina composta na Consulta de Clínica Integrada da FMDUL.

Conclusões: Um método alternativo, envolvendo o uso de uma agulha de irrigação e cola de cianoacrilato, permitiu a remoção do instrumento fraturado do interior do sistema canalar. O método é simples, económico e, ao mesmo tempo, pode resultar num sucesso previsível, podendo ser utilizado com facilidade pelo médico dentista generalista e/ou especialista na ausência de outros sistemas de remoção de instrumentos. http://doi.org/10.24873/j.rpemd.2018.11.389 